\title{
A Study on the Culture of Confucian Merchants and the Corporate Culture based on the Fit between Confucianism and Merchants
}

\author{
Zhang BaoHui ${ }^{1,2, a}$ \\ ${ }^{1}$ School of Business Administration, Shandong Women's University, Jinan, 250300, China \\ ${ }^{2}$ Management Committee of Binzhou National Development Zone of China, Binzhou, Shandong, 251000, \\ China \\ azhangbaohui@126.com
}

Keywords: The path of cultural fit of Confucian merchants and corporate culture.

\begin{abstract}
By consulting a large number of documents on Confucian business culture and enterprise culture, this paper finds out the importance and urgency of their application in business management, and establishes theoretical models and research models. With the help of quantitative questionnaire survey and statistics, this paper draws a conclusion of the degree of agreement between the two, and puts forward the realization path and improvement suggestions of the combination of Confucian and corporate culture, which is enterprise culture management, especially the innovation and breakthrough in the practice and application of Confucian merchants' culture.
\end{abstract}

\section{Introduction}

Confucian merchants, that is, the combination of Confucianism and Shang, not only have Confucian morality and intelligence, but also business excellence and success. For more than two thousand years, Confucianism, which has been spreading for a long time, has influenced the Chinese people's thinking and formed their unique behavior and mode of thinking. Chinese Confucian business culture has been advocating harmony and wealth, win-win business philosophy, can be said, this is a very long-term vision and sustainable development of the enterprise wisdom. Confucianism contains the rich wisdom of our sages in exploring the true meaning of the universe, society and life. The ancients said that "morality, utilization and good health" are three things, and the latter two are not the advantages of Confucianism. Engaged in Economic activities are not simply to make money or earn a living, but an art of management, which is to create and form a culture. The concept of the spirit of Confucian merchants refers to the unique corporate personality and code of conduct formed by the aid of Confucian businessmen. The so-called Confucian merchants mean that as businessmen, they should have the spirit of Confucianism, the magnanimity of Confucianism, and the moral norms of Confucianism. Taking the Confucian moral ideal and moral pursuit as the criterion to engage in business and do business, it permeates the "benevolence, righteousness, propriety, wisdom and faith" advocated and practiced by Confucianism in its enterprise behavior. Confucian merchants' culture is one The philosophy of "honesty", "mean", "benevolence", "Lire", "talent" and "win-win" is emphasized. Wisdom and knowledge, virtue and integrity, the responsibility to repay the society, from Zigong, we saw the earliest Confucian business style, but also the true spirit of Confucian merchants. Zigong's business activities, with its high intellectual, noble moral, high sense of social responsibility, created the first Chinese Confucian culture, no doubt called the first Chinese Confucian businessman.

Nearly 100 years, because of the rapid development of science and technology, and driven by information, transportation. The rapid progress of et al not only reduces the space distance of people, accelerates the speed and frequency of communication, but also accelerates the pace of people's life. At this time, it not only inspires the consciousness of "solidarity" in global affairs, but also breaks through the limitation of the boundary barrier of the past gradually in the face of all kinds of problems. The trend of "global" (Globalization) has become an irresistible trend. In such an era of 
rapid progress, international competition is growing To become fierce. Industry and commerce, whether in product $\mathrm{R} \& \mathrm{D}$, design, operation strategy, and even, enterprise organization and management model. At the same level, they must be able to show their broad "vision", pay attention to the "pulsation" of international development at any time, and then draw from the strengths of people in order to make up for their shortcomings and make the development of their own enterprises a global benchmark. The disparity between the rich and the poor on our planet is growing more and more. If the people with money and power have no culture to bear, without a sense of responsibility for the progress of mankind, the earth will not have peace and prosperity. It can be said that advocating the Confucian spirit among businessmen is a great cause for businessmen to gradually have "cultural responsibility". An objective requirement of progressive business ethics. We emphasize the modern value of the Confucian merchants' spirit and emphasize that we should serve the real economic development by carrying forward the Confucian merchants' spirit.

\section{What else is the Confucian spirit?}

We can understand it by the way of being regarded as the representative of Confucian businessmen in Chinese history. Business is the key to gaining market access; to make business prosperous as a way of "peace", they are all businessmen and not their own interests, but business but to enrich the people and strengthen the country, social stability as their own responsibility, are in the process of business to realize their own value in life.

The theoretical significance and practical significance of the correspondence path between Confucian businessman culture and corporate culture

Confucian merchants' culture advocates economic development based on morality, which is a "double-edged sword". It not only restricts the Confucian merchants' own honest management, but also enhances the reputation of Confucian merchants and reduces the costs and risks of social transactions. Promote the prosperity of enterprises and economic development. The 21st century is the era of cultural management, is the era of cultural enrichment. The importance of corporate culture will be the core competitiveness of enterprises and the most important content of enterprise management. The importance of corporate culture has its own culture, in order to make the enterprise have the vitality of life, the symbol of real personality, the survival, development and development of the enterprise. Strengthen, serve the foundation for the whole society. In China and the world economic arena, the protagonist of the cultural war will be a large number of Confucian businessmen. The way to realize the modern management of Confucian culture is especially important. Especially, it is of great practical significance to combine Confucian culture with modern enterprise management culture and find a new way to realize it.

\section{The necessity of the combination of Confucian and Corporate Culture}

In the face of increasingly fierce market competition, the need to continue to deal with the challenges from home and abroad. In order to carry out the enterprise management effectively and maintain the sustainable development of the enterprise, it is necessary to realize the effective integration between the Confucian culture and the enterprise culture, and to achieve symbiosis and two-way interaction. As an enterprise manager, it has become an important way for enterprises to improve their core competitiveness by deeply analyzing the relationship between management system and corporate culture and correctly handling the relationship between them. Corporate culture covers the material culture, behavior culture, institutional culture and spiritual culture of the enterprise, whether it is the external performance of the enterprise, or the internal spirit. Is a component of corporate culture.

\section{Deficiency and existing problems in the study of Confucian Culture at pres}

The ideological confusion caused by the coexistence of Confucianism and Western thought is 
mainly manifested in the opposite thinking: the antithesis between tradition and modernity, between reason and belief, and between individual and group. Contrast instrumental rationality with value rationality. Due to the one-sided emphasis on instrumental rationality, positivism was later popular, and positivism led to the scientific trend of blindly worshipping instrumental rationality. As a result of one-sided derogation of value rationality, the damage of humanistic spirit, the distortion and alienation of personality, the formation of "unidirectional people", which leads to the loss of the world of meaning and the world of spirit. Because of the one-sided emphasis on the role of the individual The emphasis on the competition between people leads to the popularity of individualism and the serious antagonism between individuals and groups, which damages the mutual aid and harmony of social groups. Therefore, the western modernity can not but be manifested as the reverse of the two laws: on the one hand, it promotes the process of modernization, on the other hand, it leads to the prevalence of "modern diseases". The overwhelming new things also symbolize the advent of the so-called "knowledge economy" (Knowledge Economy) era. In order to make our economy develop healthily and orderly, business management must advocate the spirit of Confucian businessmen, and must advocate progressive business ethics, otherwise, Our economy is unlikely to be healthy and orderly. Sustained and stable development. As entrepreneurs and scholars, how can we not embrace the thinking of "looking ahead", grasp the pulsation and development trend of the times at any time, step by step, and let enterprises "keep pace with the times". In the aspect of the matching path between Confucian culture and enterprise culture, the research results of the method and path of guiding practice are urgent and lack of innovative research results.

\section{Methods and tools studied in this paper}

By reading a large number of literature, establishing theoretical models and research framework, this paper adopts questionnaire surveys and field visits to 160 Chinese enterprises advocating Confucian business culture. According to the reliability and validity, the paper adopts a scale of 7 levels. And use SSPS18 software to carry on the measurement analysis, draw the conclusion of the research.

\section{The formation and comparison of Confucian and Corporate Culture and the idea of fit}

\subsection{The connotation of Confucian merchants}

The Confucian merchant culture takes Confucian values and moral values as its orientation, which reflects the way of thinking and norms of dealing with daily business, business dealings and people. It has its own unique cultural pattern.

\subsection{What is fit?}

Fit is a Chinese word, refers to the same, the same spirit. For example: monarch and minister agree. Out of Tang du Fu's poem: "the plan is suitable for war, the agreement is clear and harmonious." [agreement]: vote, spirit and spirit are the same. The monarch and the minister agree. [in keeping with]: conformance. To join one another in a similar spirit. Accord with.

\subsection{Humanist Confucian Merchants and Modern Confucian Merchants}

Chinese Confucian traditional culture has always centered on the humanities, so-called humanities, simple is the truth of life. Therefore, Confucian humanism is "benevolence" is to put people in a broad sense (more than two people) to examine and teach, "culture" is from the humanities, from the inside outside. Pursue the character of the gentleman, pursue the realm of the gentleman, and strive to cultivate himself into a gentleman of all kinds. The modern Confucian merchants should have the scientific and technological expertise and the Confucian value ideal, that is, the management managers with the "talent of the spirit of the scholar". The Confucian business 
culture is oriented by the Confucian values and ethics, which embodies the Chinese Confucian merchants. There is a unique cultural model in the way of thinking and dealing with people in daily operation, business dealings and human affairs.

\subsection{What does corporate culture mean?}

Corporate culture, or (Corporate Culture or Organizational Culture), is a unique cultural image of an organization that consists of its values, beliefs, rituals, symbols, ways of doing things, etc., Is the enterprise in the daily operation of each side of the performance. Confucian business culture is an important means to strengthen enterprise management and enterprise culture construction. The culture of Confucian merchants is summed up through the successful practice of Confucian merchants in the past dynasties, and it is a way of enterprise management. Many contents of Confucian and Commercial Literature libation in the Development of Today's Enterprises In order to solve the problems in modern enterprise management, the enterprise leader has the enterprise culture by applying the function of "culture changer" to the enterprise.

\section{Empirical study}

\subsection{Theory model}

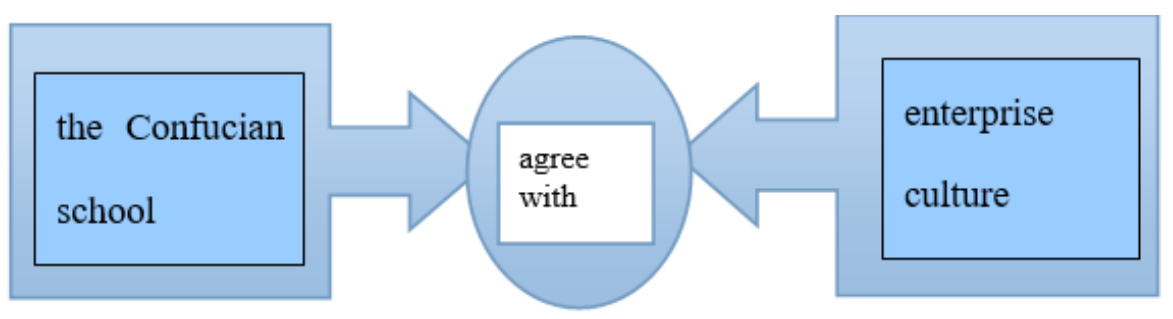

\subsection{Research framework}

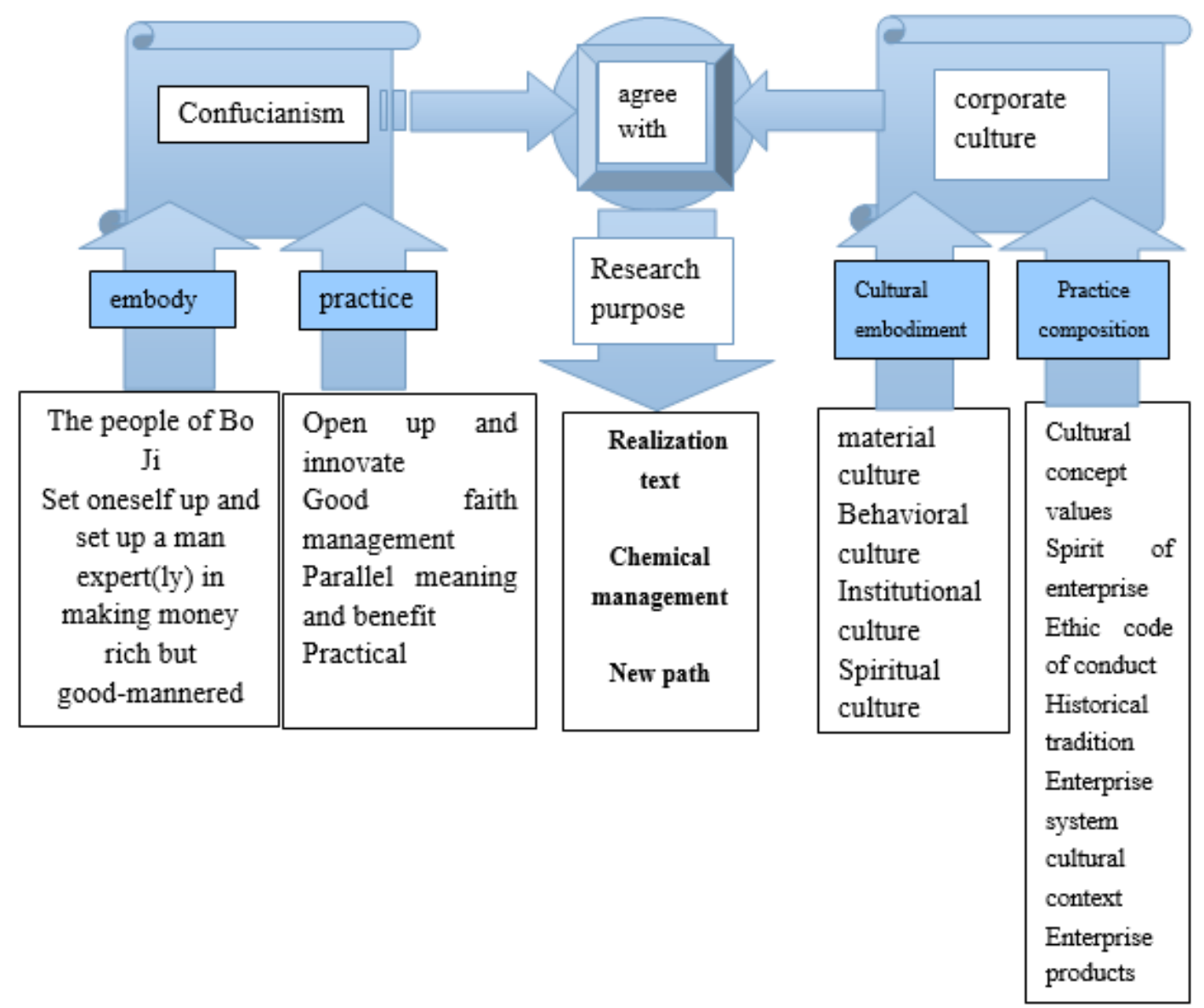




\subsection{Variable selection}

Each variable in the questionnaire, the measurement performance is 7 levels. Then use the SSPS software statistical processing.

\subsection{Quantitative analysis}

The data were analyzed by 525 valid enterprise questionnaires. The results of measurement are as follows:

In the measure, variables also concern that the Confucian merchants should have the following main characteristics: a. Adhere to the practice of "benefit" and "justice" of the values of unity; c. dare to compete and be good at competition; d. carry out people-oriented management; e. have the consciousness and ability to open up and innovate. These are the most basic qualities that modern Confucian merchants must possess, but not all of them.

In 1921, Confucian merchants culture in the embodiment, the higher degree of agreement is to generate wealth, rich and courteous, worthy of recognition and promotion. The general degree of compatibility is that Bo Ji sentient beings need to be strengthened in the corporate culture, and those with a lower degree of fitness should pay special attention and focus on promotion.

In 2001, the Confucian merchants culture in practice, the high degree of agreement is good faith management, justice and benefit parallel, worthy of recognition and promotion. In general, the degree of conformity needs to be strengthened in the corporate culture, and the less suitable degree is to open up and innovate, which should be paid special attention to and be promoted, which shows that the Chinese Confucian culture has its inherent defects in innovation.

In the aspect of embodiment of corporate culture, institutional culture and behavior culture are the most suitable ones, which are worthy of recognition and promotion. The general degree of conformity is spiritual culture, which needs to be strengthened in the corporate culture, and the lower degree of fitness is material culture, which should be paid special attention to and promoted. It is shown that Chinese enterprises are short board in the aspect of Confucian merchants' hardware culture and visual culture. There is an urgent need for promotion.

In practice, enterprise spirit, values and moral standards are the most suitable for corporate culture, which is worthy of recognition and promotion. The general degree of conformity is the cultural concept, the enterprise system needs to be strengthened in the corporate culture, and the lower degree of conformity is the cultural environment, the code of conduct, the products of the enterprise, and the historical tradition. It also shows that the cultural environment and historical tradition of Confucian merchants in Chinese enterprises are not good enough and should be paid attention to by the government. Code of conduct, enterprise products, historical tradition will be the focus of the cultural construction of Confucian businessmen and the top priority.

\section{Implementation path and conclusion}

\subsection{It fits the path principle of enterprise culture construction of Confucian merchant culture}

Cultural management should be combined with strategic management of enterprises.

The corporate culture, which fits the culture of Confucian merchants, should be oriented to the future and reflect the characteristics of the industry and the personality of the enterprise to play the core role of the enterprise leadership group.

Cultural management and image management promote the establishment of cultural system.

\subsection{Conclusion}

The corporate culture of Confucian merchants culture depends on many complicated factors. In general, the corporate culture of Confucian merchants culture can improve the degree of compatibility under certain constraints. However, the obstacles in the operation process still need to be realized effectively through study and research, and theoretical innovation and policy support should be carried out if necessary, so that the corporate culture, which fits the Confucian culture, adds management value and avoids the role of "good medicine and wrong service". "Confucian 
business thought" is the oriental value and thought mode embodied in eastern management, which is used to make up for the deficiency of instrumental rationality and analytical thinking in "western business thought". "Confucian". The "Confucian culture" and the "merchant" emphasis on practical results and careful calculation complement each other, forming the enterprise culture with the characteristics of Confucian merchants, which is applied to the practice of industry and commerce. It is an ideal management mode to meet the requirements of modern enterprise management and is destined to prevail. Advocate: with the essence of Confucianism, cast the soul of Shang Tao.

\section{References}

[1] Yang B jun. Translation of the Analects of Confucius [M]. Beijing: Z h Book Co., Ltd.

[2] Chen Q z, Zhang S h. Confucian merchants and the 21 century [M]. Q l Book Society 2004

[3] Huizhou Merchants: the first Business Group in Qing Dynasty/by Pan Xiaoping-Beijing: China Radio and Television Publishing House

[4] Ma Tao. Confucian tradition and Market economy [M]. Shanghai: Fu d University Press, 2003.

[5] Z m. The modernity explanation of Trust crisis [J]. Academic Research! 2002.4

[6] M J y, Chu Xiaoping: looking at the honesty of Chinese businessmen from the traditional culture [J]. Journal of Shanxi University of Finance and Economics

[7] Baidu knows: http: / zhidao. baidu. com. question/ 433154072. html 